\title{
Design and Analysis of Fuzzy based Node Traversal Time AODV for Improving the QoS in Mobile Ad Hoc Networks
}

\author{
K. Narasimha Raju \\ Research Scholar \\ Andhra University \\ Visakhapatnam
}

\author{
S.P.Setty, PhD. \\ Prof. Dept of CS \& SE \\ Andhra University \\ Visakhapatnam
}

\begin{abstract}
Routing is a challenging issue which should be handled in a timely manner without unnecessary time delays in MANETs. The choice of the constants affects timeliness of protocol. AODV suggests that the Node Traversal Time (NTT) should be a constant value but does not mention how this value to be adjusted with network size. The proposed method "Fuzzy Based Node Traversal Time AODV (FBNTTAODV)" suggests that the Node Traversal Time should be a suitable value with the network size and the results shows that it performs better than AODV.
\end{abstract}

\section{Keywords}

Ad Hoc Network, Fuzzy Logic, AODV, FBNTTAODV.

\section{INTRODUCTION}

Mobile Ad Hoc Networks (MANETs) [1][2][3][4][5] are collection of mobile devices that communicate with each other without the need of centralized infrastructure. One of the challenging issues [6] in MANETs is routing [7]. The routing protocols [8][9][10] can be proactive, reactive, and hybrid . The rest of the paper is organized as follows: Reactive routing protocol "AODV" is summarized in section 2, Methodology is illustrated in section 3, Simulation Environment is presented in section 4, and results is presented in section 5 and finally concluded with section 6 .

\section{AD HOC ON-DEMAND DISTANCE VECTOR ROUTING (AODV)}

Ad Hoc On-Demand Distance Vector (AODV) Protocol [12] allows users to find and maintain routes in the network in an on demand basis. If a sender wants to find a route to the destination, it broadcasts a RREQ message and then waits for NET TRAVERSAL TIME (NETT) to receive RREP message. Once the source node received the RREP message, the route has been established and data packets may be forwarded to the destination. Route Maintenance is to provide feedback to the sender in case of router or link failure through RERR message.

\section{METHODOLOGY}

AODV considers the defaults constants suggested in the draft [11] standard. The proposed method concentrates on the Node Travel Time (NTT) value which plays an important role in calculating Net Traversal Time, the value the sender waits for RREP to determine route lifetime and time-out values. The AODV suggests that the NTT value should be constant but does not mention how this value should be adjusted with network size. The proposed method" Fuzzy Based Node
Traversal Time AODV (FBNTTAODV)” suggests that the NTT should be a suitable value with the Network size.

The following are the some of the default constants in the standard.

NODE_TRAVERSAL_TIME $=40 \mathrm{~ms}$

NET_DIAMETER $=35$

NET_TRAVERSAL_TIME $=2 * N O D E \_T R A V E R S A L \_T I M E *$

NET_DIAMETER $\mathrm{ms}$.

\subsection{Fuzzy Logic Based Node Traversal Time AODV (FBNTTAODV)}

Human experiences can be implemented through membership functions and fuzzy rules in fuzzy logic [13][14][15]. This method calculates Node Traversal Time value associated with the network size and speed. The Input variables are number of nodes (nnodes) and speed. Node Traversal Time is treated as an output variable. The linguistic variable associated with input variables are Low $(\mathrm{L})$, Medium $(\mathrm{M})$ and $\operatorname{High}(\mathrm{H})$ for number of nodes, Low $(\mathrm{L})$ and High $(\mathrm{H})$ for speed and for the output variable these are Low (L), Medium (M) and High (H). $\quad$ Figure (l) shows the architecture used in the model. Figure (2), Figure (3), Figure (4) shows the membership functions and Table 1 shows fuzzy conditional rules respectively. Triangular shaped membership functions [16] are preferred for output variable. Figure 5(a) and 5(b) shows rule view for nodes 20 with NT 14.5 and for nodes 70 with NT 20.4 respectively. Figure 5(c) shows the surface view of the model.

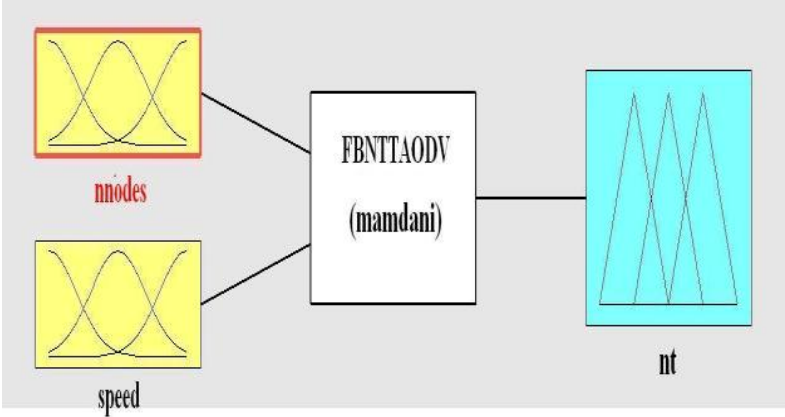

Figure(1) : Mamdani architecture of the FBNTTAODV 


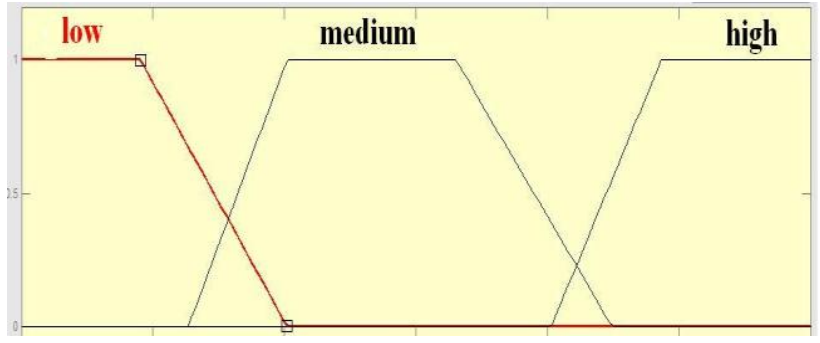

Figure (2): Membership function for Input variable nnodes

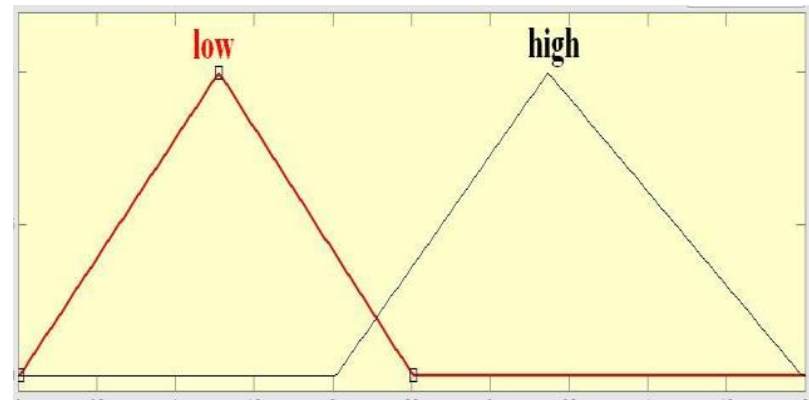

Figure(3) : Membership function for Input variable speed

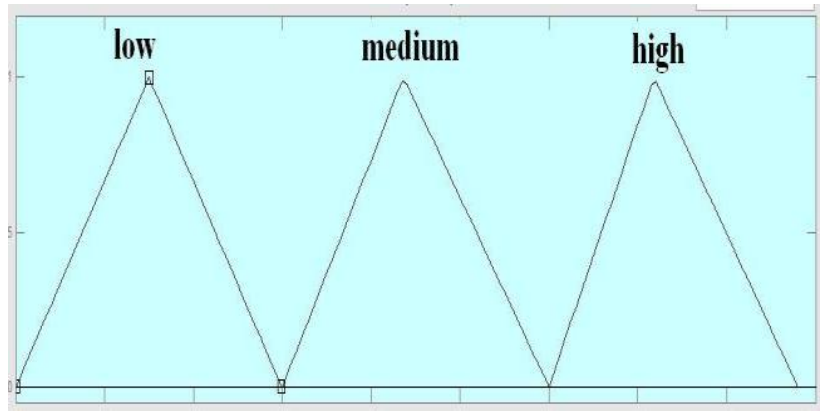

Figure(4): Membership function for output variable ' $n t$ '

Table 1: Fuzzy Rule Base

\begin{tabular}{|c|c|c|}
\hline \multicolumn{2}{|c|}{ Input Variables } & Output Variable \\
\hline $\begin{array}{c}\text { Number of } \\
\text { Nodes(nnodes) }\end{array}$ & Speed & $\begin{array}{c}\text { Node Traversal } \\
\text { Time(nt) }\end{array}$ \\
\hline $\mathrm{L}$ & $\mathrm{L}$ & $\mathrm{L}$ \\
\hline $\mathrm{M}$ & $\mathrm{L}$ & $\mathrm{M}$ \\
\hline $\mathrm{H}$ & $\mathrm{L}$ & $\mathrm{H}$ \\
\hline $\mathrm{L}$ & $\mathrm{H}$ & $\mathrm{M}$ \\
\hline $\mathrm{M}$ & $\mathrm{H}$ & $\mathrm{M}$ \\
\hline $\mathrm{H}$ & $\mathrm{H}$ & $\mathrm{L}$ \\
\hline
\end{tabular}

\section{SIMULATION ENVIRONMENT}

Simulators like NS2 [24], Glomosim [25] and Qualnet [26] etc., were developed to evaluate the performance [17][18][19][20][21][22][23] of routing protocols. The experiments for evaluating the FBNTTAODV model were implemented within the Qualnet Library. The simulation parameters used in the method was given in table 2 .

Table 2: Scenario Parameters varying number of nodes

\begin{tabular}{|c|c|}
\hline Routing Protocols & AODV \\
\hline Area & Two00 x $1000 \mathrm{~m}$ \\
\hline Simulation Time & CBR \\
\hline Propagation Model & \\
\hline Traffic & 512 bytes \\
\hline Packet size & $20,30,40,50,60,70,80$ \\
\hline Nodes & Omni directional \\
\hline Antenna Type & $250 \mathrm{~m}$ \\
\hline Transmission range & $250 \mathrm{~m}$ \\
\hline Receiving range & 802.11 \\
\hline MAC layer & $0 \mathrm{sec}$ \\
\hline Pause time & $1 \mathrm{~m} / \mathrm{s}$ \\
\hline Min Speed & \\
\hline
\end{tabular}

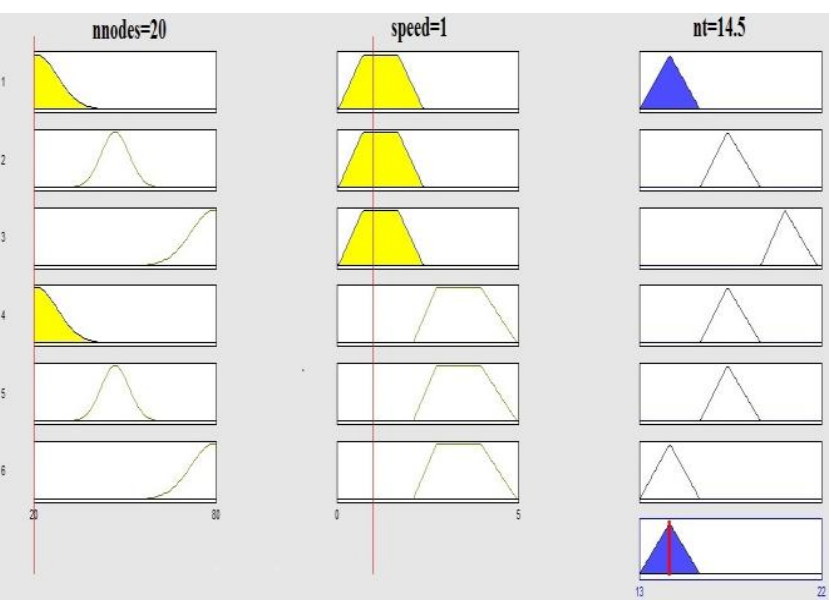

Figure 5(a) : Rule view for 20 nodes, speed $1 \&$ nt 14.5 


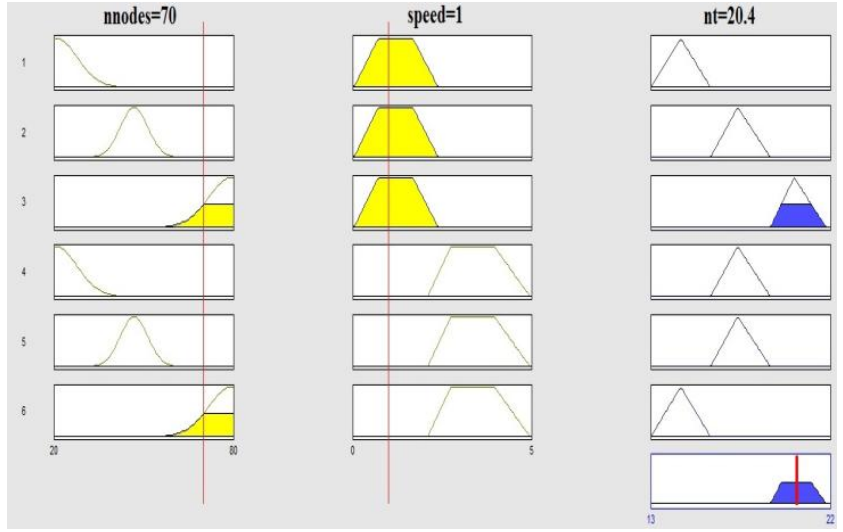

Figure 5(b) :Rule view for 70 nodes, speed 1 \& nt 20.4

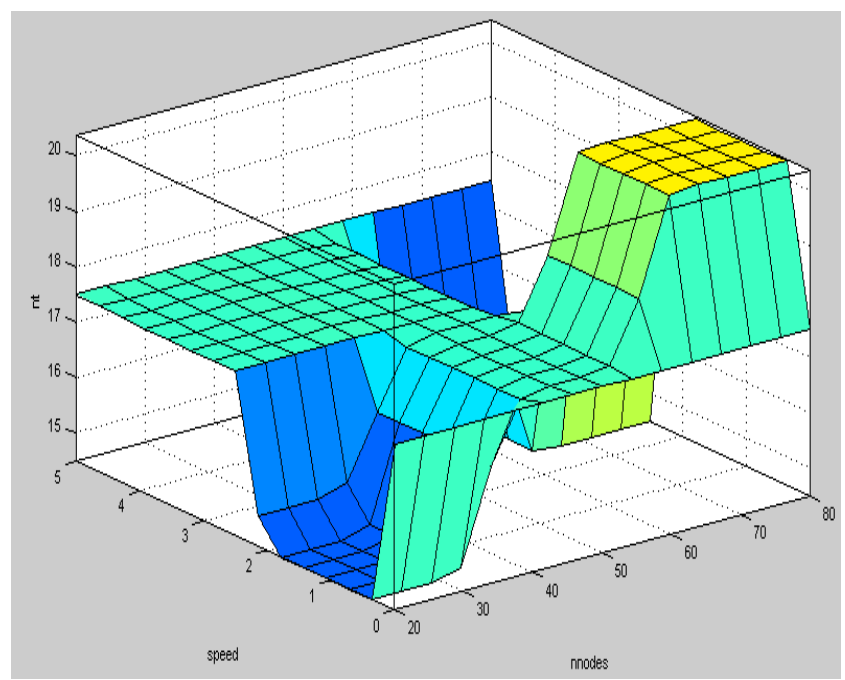

Figure 5(c) : Surface view showing speed, nnodes and nt

\section{RESULTS AND ANALYSIS}

The performance metrics namely Average end-end delay, Average jitter, Throughput and Packet delivery ratio were considered to analyze FBNTTAODV reactive routing protocol.

Average Jitter: The delay variation between each received data packet. The Average jitter is shown in the figure (6) with number of nodes.

Average end-end delay: The time taken for a packet to travel from a source to destination. The Average end-end delay is shown in the figure (7) with number of nodes.

Throughput: The total amount of data received by the receiver from the sender divided by the time takes for the receiver to get the last packet. The Throughput is shown in the figure (8) with number of nodes.

Packet Delivery Ratio: The fraction of packet sent by the applications that are received by the receiver. The packet delivery ratio is shown in the figure (9) with number of nodes.

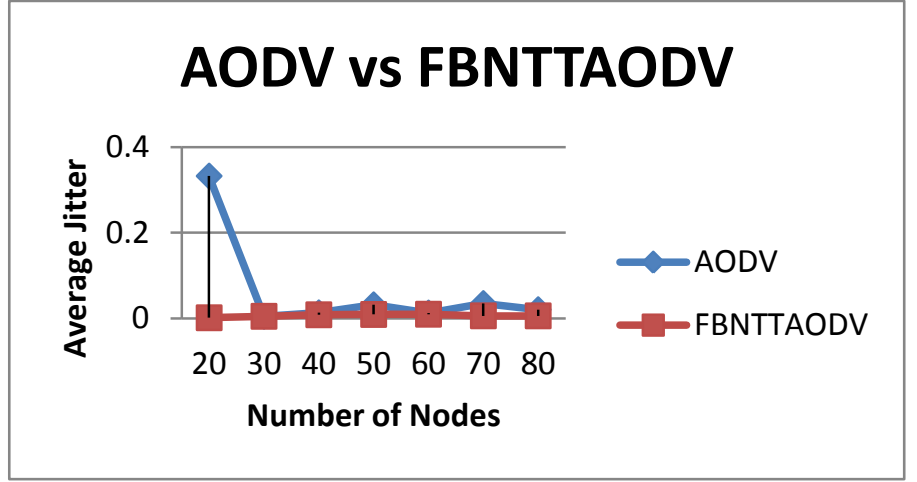

Figure (6): Variation of Average jitter with number of nodes

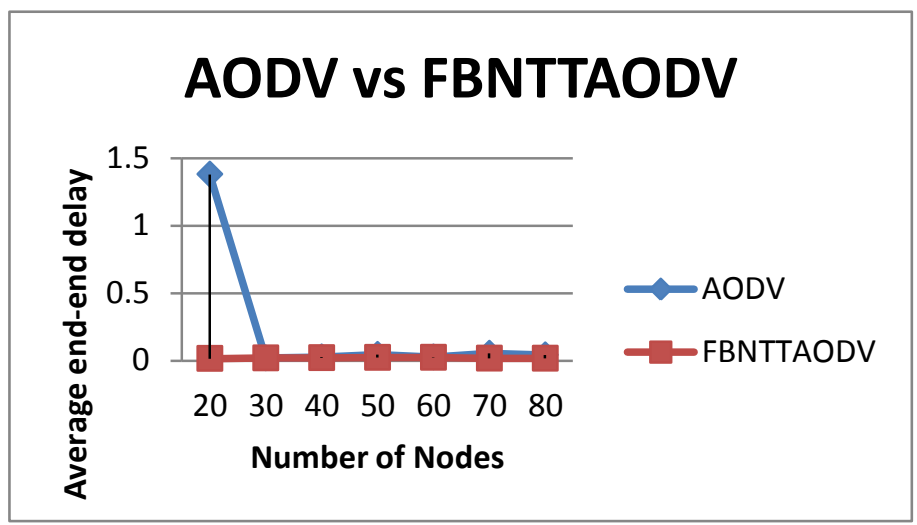

Figure (7): Variation of Average end-end delay with number of nodes

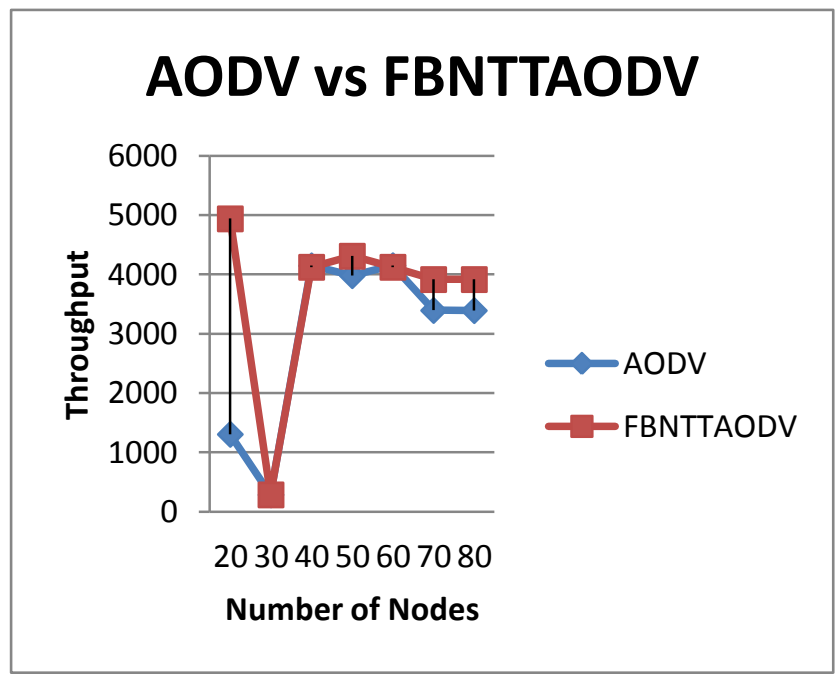

Figure (8): Variation of Throughput with

Number of nodes 


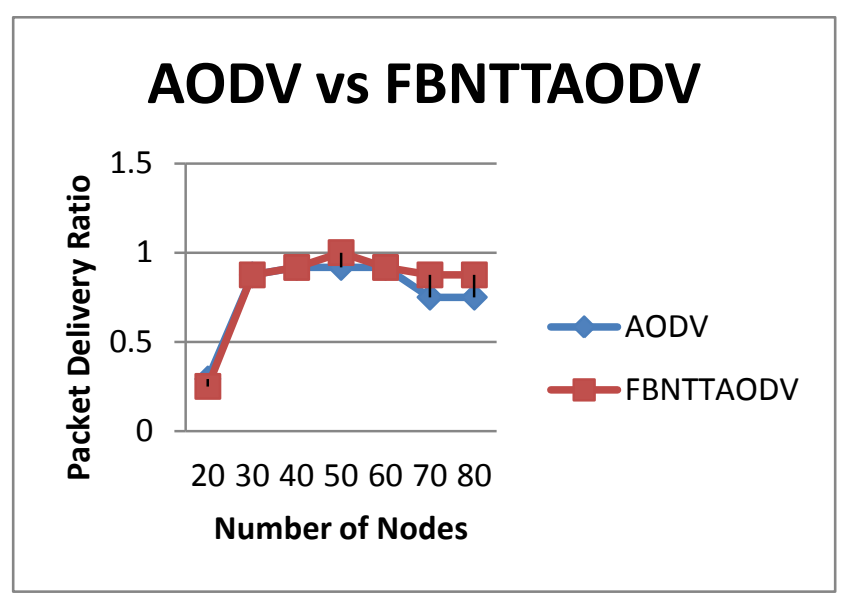

Figure(9): Variation of Packet Delivery Ratio with number of nodes

\section{CONCLUSION AND FUTURE SCOPE}

Varying node traversal time with the network size and speed plays a major role for improving the performance. From the simulation results, it was observed that at 20 nodes, the average jitter for AODV and FBNTTAODV was 0.332374 and 0.0017 respectively. From the results, it is evident that FBNTTAODV performs better than AODV in the above QOS metrics. The given model with various mobility models can further be studied.

\section{REFERENCES}

[1] Iiyas, M., 2003. The Hand Book Of Ad Hoc Networks, CRC Press.

[2] Perkins C., Ad Hoc Networking, Addison Wesley, 2001.

[3] D. P. Agrawal and Q-A Zeng. "Introduction to Wireless and Mobile Systems," Brooks/Cole Publishing, ISBN No. 0534-40851-6, 436 pages, 2003.

[4] Siva, C., R. Murthy and B.S. Manoj, 2004. Ad Hoc Wireless Networks Architectures and Protocols . Prentice Hall.

[5] C.-K. Toh, Ad hoc MobileWireless Networks: Protocols and Systems, Prentice-Hall PTR, Englewood Cliffs, NJ, 2002.

[6] S. Giordano and W. W. Lu, "Challenges in mobile ad hoc networking," IEEE Communications Magazine, vol. 39, no. 6, pp. 129-181, June 2001.

[7] David B. Johnson ,"Routing in Ad Hoc Networks of Mobile Hosts," in Proceeding of the IEEE workshop on Mobile Computing Systems and Application, Dec 1994.

[8] Hongbo Zhou, "A Survery on Routing Protocols in MANETs," Technical. Note March 2003.

[9] J. Broch, D. Maltz, D. Johnson, Y. Hu, and J. Jetcheva. "Multi-Hop Wireless Ad Hoc Network Routing Protocols." ACM/IEEE International Conference on Mobile Computing and Networking (MOBICOM'98), pages $85-97,1998$.
[10] E. M. Royer, and C.-K. Toh, "A review of current routing protocols for ad hoc mobile wireless networks", IEEE Personal Communications, Apr. 1999, pp. 46-55.

[11] C.E. Perkins, E.M. Royer \& S. Das, Ad Hoc On Demand Distance Vector (AODV) Routing, IETFInternet draft, draft-ietf-manet-aodv-08.txt, March 2001.

[12] Perkins C. and Royer E.M., "Ad-Hoc on-Demand Distance Vector Routing," in Proceedings of the $2^{\text {nd }}$ IEEE Workshop on Mobile Computing Systems and Applications, New Orleans, LA, pp. 90-100, February 1999.

[13] T. J. Ross, Fuzzy Logic With Engineering Applications. New York: McGraw-Hill, Inc., 1995.

[14] L. A. Zadeh, "fuzzy logic = computing with words", IEEE Transactions on fuzzy systems, vol. 4, no2, pp. 104-111, 1996

[15] Kosko, B., Fuzzy Thinking, Hyperion, 1993.

[16] Pedrycz W., "Why Triangular Membership Functions?," Fuzzy Sets System, Vol.64, pp.21-30,1994.

[17] A. Nasipuri, R. Castaneda, and S. R. Das, "Performance of multipath routing for on-demand protocols in ad hoc networks," Mobile Networks Applicat. (MONET) J., vol. 6, no. 4, pp. 339-349, 2001.

[18] C.-E. Perkins, E.-M. Royer, S.-R. Das, and M.-K Marina, "Performance comparison of two on-demand routing protocols for ad hoc networks," IEEE Personal Communications, vol. 8, no. 1, pp. 16-28, Feb 2001.

[19] S. -J. Lee, M. Gerla and C. -K. Toh, "A Simulation Study of Table-Driven and On-Demand Routing Protocols for Mobile Ad Hoc Networks," IEEE Network, July-August 1999, Vol. 13, No. 4, pp. 48-54.

[20] $\boldsymbol{S}$. Corson and J. Macker. Mobile Ad Hoc Networking(MANET) Routing Protocol Performance Issues and Evaluation Considerations. Technical report, Request for Comments : 2501, January 1999.

[21] J. Broch, D. Maltz, D. Johnson, Y.-C. Hu, and J. Jetcheva, "A Performance Comparison of Multihop Wireless Ad Hoc Network Routing Protocols", ACM/IEEE Mobile Computing and Networking, Octobre 1998.

[22] S.P.Setty et.al,"Performance Evaluation of AODV in different Environments", International Journal of Engineering Science and Technology (IJEST), Vol.2(7), 2010, 2976-2981.

[23] Huang R, Zhuang Y, Cao Q, " Simulation and Analysis of Protocols in Ad Hoc Network", 2009 International Conference on Electronic Computer Technology, 2009 IEEE.

[24] Network simulator -2. http://www.isi.edu/nsnam/ns/

[25] GLOMOSIM http://pcl.cs.ucla.edu/projects/glomosim/

[26] QualNet Network Simulator, Available: http://www.scalable-networks.com 